\title{
Radicular pain due to epidural gas-containing pseudocyst. Report of two cases and review of the literature
}

\begin{abstract}
Introduction:Intradiscal gas generated from degenerative disc phenomena is called vacuum or pneumodisc. It is mainly caused by primary intervertebral osteochondrosis. It has a high prevalence in elderly population. The migration of this gas to the spinal canal can generate cord or root compression and result in radiculalgia or canal stenosis. We describe two cases of radicular pain due to aerial pseudocyst diagnosed and treated in our center and review the available reports.
\end{abstract}

Conclusion: The radicular pain originated by epidural gas-containing pseudocyst is an unusual diagnosis, for which there is no consensus regarding the diagnosis methods and its treatment. We consider computed tomography to be the most specific study and we suggest surgical resolution by decompression and microreseccion of the cyst when conservative treatment is not effective.

Keywords: intervertebral disc degeneration, intervertebral disc disease, Vacuum, surgical decompression, sciatica
Volume 5 Issue 2 - 2018

\section{Matias Pereira Duarte, Agustin Maria \\ Garcia Mansilla, Maximiliano Mereles, Julio \\ Bassani, Matias Gustavo Petracchi, Marcelo Gruenberg, Carlos Alberto Sola}

Instituto de Ortopedia y Traumatologia, Hospital Italiano de Buenos Aires, Argentina

\begin{abstract}
Correspondence: Matias Pereira Duarte, Instituto de Ortopedia y Traumatologia, Hospital Italiano de Buenos Aires, Ciudad Autónoma de Buenos Aires (CABA), Capital Federal, Argentina, Tel +549 (I I) 62225945 ,

Email matias.pereira@hospitalitaliano.org.ar
\end{abstract}

Received: January 23, 2018 | Published: April 26, 2018
Abbreviations: X-Rays, radiographs; CT, computed tomography; MRI, magnetic resonance imaging; NSAIDs, nonsteroidal anti-inflammatory drugs; EMG, electromiogram; D, decompression; CR, cyst resection; S, satisfactory; R, recurrence; HIBA, hospital italiano de buenos aires

\section{Introduction}

The intradiscal vacuum phenomenon is generated by the release of gas from discal degeneration, depositing in the fissures of the intervertebral discs. ${ }^{1-4}$ Its incidence varies between $3 \%$ to $20 \%$ in radiographs (X-rays) $)^{5,6}$ up to $50 \%$ of patients, older than 40 years old, studied with computed tomography $(\mathrm{CT}){ }^{7}$ The migration of gas accumulated in the intervertebral spaces to the spinal canal can generate cord and/or root compression, triggering an incapacitating ciatalgia or canal stenosis symptoms. This event is scarcely reported in the literature and there is no established consensus for its evaluation and treatment. ${ }^{8-13}$

We present two cases of radicular pain, diagnosed and treated in our institution, resulting from a gas-containing pseudocyst compression at the root recess of L4-L5 and L5-S1 spaces, treated surgically by simple laminotomy and microresection of the pseudocyst.

\section{Case presentation}

\section{Patient I}

A 73-year-old female patient with a history of a lumbar stenosis consulted for left ciatalgia of four months of evolution. She presented a positive Lasegue maneuver with preserved strength and sensibility. The patient's X-rays demonstrated slight spondylotic changes and in the CT a hypodense area was detected within the spinal canal at left L5-S1 recess level (Figure 1A \& 1C). The Magnetic Resonance Imaging (MRI) showed, adjacent to the fifth disc, on the left side, a hypointense image in all the sequences, which did not enhance with intravenous contrast, compatible in both studies with a disc-origin cyst of gaseous content (Figure 1B \& 1D).

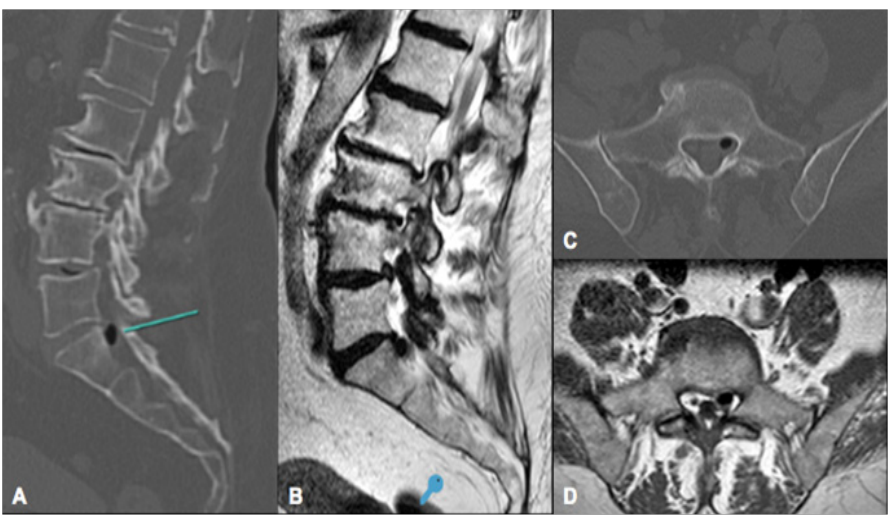

Figure I Patient I, 73-year-old female patient. A and C) Sagital and axial views of CT-scan showing a hypodense area (green line) within the spinal canal at left L5-SI recess level; B and C) Sagital and axial views of RMITI secuence demonstrate a hypointense image with regular edges, adjacent to the fifth disc, on the left side, that seems to be in continuity with the intervertebral disc (B).

The patient presented a poor response after a period of 8 weeks of conservative treatment with non-steroidal anti-inflammatory drugs (NSAIDs), pregabalin, rest and a left L5-S1 periradicular blockage. A left L5-S1 laminotomy was performed associated with cyst resection. We corroborated gaseous content in the cyst and the correct release of the compressed root. The patient was discharged at 24 hours, re-evaluated at 4, 15 and 60 post-surgical days with no symptoms recurrence. At 12 months postoperatively, the patient only presents occasional mechanical low back pain. 


\section{Patient 2}

A 61-year-old male patient presented with invalidating low back pain and left sided leg irradiation. Pain exacerbation with Lassegue maneuver was found, without motor or sensory deficit. No response was achieved after three months of NSAIDs treatment.

Anterior-posterior (AP) and lateral lumbosacral X-Rays were performed as well as lumbosacral MRI (Figure 2A \& 2B). At T1 and T2 MRI sequences, a hypointense cystic image was found at L5-S1 disc level. Posteromedial left sided extension displaced the corresponding root. To certify the disc origin of this gaseous collection, we perform discography (Figure 2C). The manometry of the fifth lumbar disc reflected an intense low back and left sciatic pain similar to that previously reported by the patient. The control images demonstrated a cystic lesion connected to the fifth lumbar disc, with contrast inside, confirming the diagnosis of gas-containing pseudocyst.

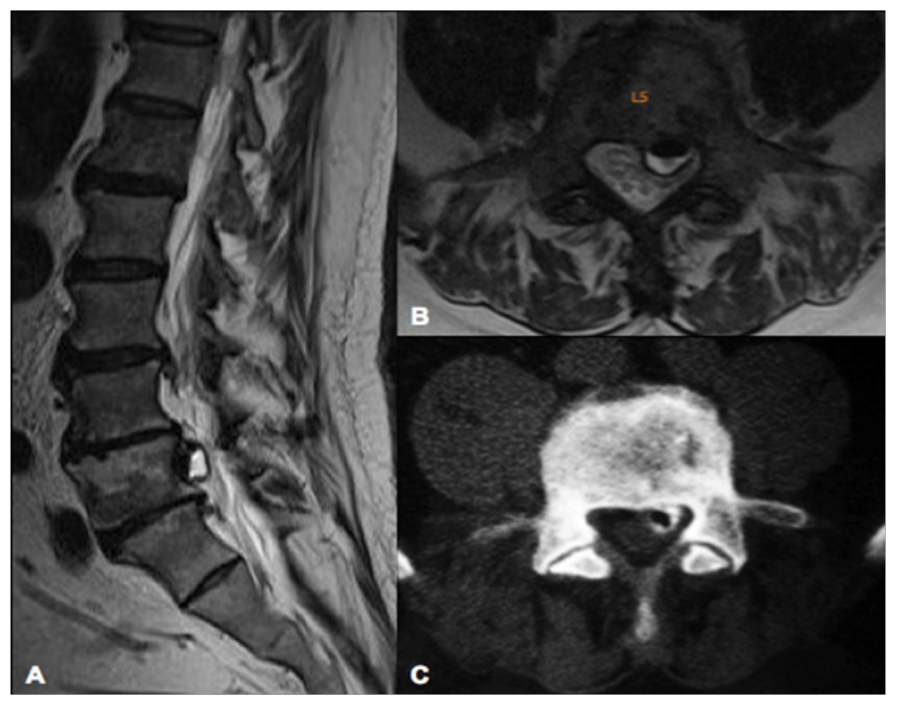

Figure 2 Patient 2, 6I-year-old male patient. A and B) Sagital and axial views of RMITI secuence that demonstrate a hypointense image with regular edges behind L5 vertebral body with a liquid level inside; C) Axial view of CT-sacan after discograpfy showing a hypodense area with contrast surrounding it, that confirms disc communication with the air content of the pseudocyst.

The patient did not respond to a periradicular blockage so laminotomy and microresection of the cyst were performed, decompressing the root involved. After seven postoperative days, the patient resolved his symptoms and at seven years of follow-up, the patient did not have symptoms recurrence.

\section{Discussion}

In a cadaveric study of 400 columns, Resnick et al. ${ }^{14}$ describe the main causes of gas formation in the intervertebral spaces: vertebral osteomyelitis, Schmorl nodules, spondylosis deformans, vertebral collapse with osteonecrosis and primary intervertebral osteochondrosis. The most frequent cause is the intervertebral osteochondrosis. This phenomenon, also called vacuum phenomenon has a high incidence, mostly in elderly patients. Even though, the migration of gas from the intervertebral space to the spinal canal is extremely rare.

There is no diagnostic algorithm nor standardized treatment for radiculopathy due to gas-containing pseudocystic (Table 1). Lunardi et al. ${ }^{9}$ reported a case of a 62 -year-old female patient with bilateral sciatica, they used CT scan for diagnosis and performed a resection of the pseudocyst filled with gas, obtaining good clinical results. Cheng et al (11) reported two cases studied with electromyogram (EMG), $\mathrm{CT}$, myelography guided by computed tomography (myelo-CT) and MRI. A partial hemilaminectomy was performed in both cases, with symptoms resolution. Orrison and Lilleas as well as Kaiser et al. ${ }^{15,17}$ reported cases studied with Myelo-CT and CT for diagnosis. However they do not refer to the treatment performed or its results.

Anda et al. ${ }^{8,16}$ published two cases in 1987 and 1988. In the first one, they described a patient consulting for recurrence of radicular pain after a postoperative year of microdiscectomy. CT was carried out evidencing air in the intradural space. Surgical resolution required a durotomy and evacuation of gaseous content from the intradural space. In the second report, root compression due to air bubble was studied with lumbosacral X-Rays and CT scans. In this case conservative treatment was indicated with symptoms resolution. Other authors ${ }^{18-12}$ reported cases of air pseudocyst producing radicular pain diagnosed by $\mathrm{CT}$ and myelo-CT, treated by decompression and resection, achieving good postoperative results.

Bosser et al. ${ }^{23}$ reported a 60 -year-old patient treated by CT-guided puncture, presenting transient relief of symptoms, with recurrence 5 days later, requiring surgical approach as definitive treatment. Kakitsubata et al. ${ }^{13}$ in 2009 present four cases in which they use discography as a diagnostic method. One of the four cases was treated by laminectomy and discectomy, obtaining good results after one year of follow-up. In the second case, conserrvative treatment was elected with analgesics, oral steroids and physical therapy. After 14 months of follow-up, the patient did not present pain or sensory alterations in his affected limb. The third patient was treated surgically, the cyst resection could not be effective due to firm adhesions, so a puncture was performed. The patient had immediate relief of his symptoms. The last patient described in this report was also treated surgically by percutaneous puncture, achieving a gradual recovery of affected limb function and disappearance of pain. The largest series of cases found in the literature was published by Sung Uk Kuh et al. ${ }^{24}$ who presented 61 patients with 69 gas-containing epidural pseudocysts diagnosed with CT and MRI between 2005 and 2010 in the same institute. Twenty-two out of these were treated surgically due to motor or sensitive alterations or loss of sphincters control.

The twenty-two surgical patients and its twenty-five affected leves were divided according to:

a. Location: Two L2/L3; one L3/L4; fifteen L4/L5 and sevenL5/S1.

b. Type of compression: Twelve were located ah the central canal $(48 \%)$; eight were foraminal (32\%) and five extraforaminal (20\%).

c. Surgical treatment: Decompressions and arthrodesis was performed in twelve patients who were diagnosed concomitantly with canal stenosis or previous segmental instability; decompressions and pseudocyst resection was indicated for the other ten patients.

No specific treatment was clarified for the patients who did not present surgical criteria, but they all resolved their symptoms. We used $\mathrm{X}$-rays, CT and MRI as diagnosis imaging studies and a discography was required in the second case to confirm disc communication. We believe that the first three are essential for the study of a patient 
with radicular pain. Although discography is the most sensitive and specific instrument for this condition, it has a tendency towards disuse as it is an invasive method and has several morbidities such as pain exacerbation. Even more, it is the only study that allows to demonstrate the communication of the degenerative nucleus pulposus with the cystic content. This is the reason why CT is the most useful imaging study according to the cost benefit relationship.

In our center, patients with these symptoms are initially indicated with conservative treatment, depending on symptoms severity and disability. It consists in NSAIDs, neuropathic pain modulators such as gabapentin or pregabalin, physical therapy and even periradicular blockages guided by CT-scans. When non effective, we indicate decompression and cyst resection. We aknowledge we present a small number of cases, but this is a rarely reported condition. Our review intents tu sum up avairable literature in order to dicern criteriously the gold stardart for studing and treating this patients.

Table I Comparative table of literature review of gas-containing pseudocyst. Imaging studies, treatment and outcomes

\begin{tabular}{|c|c|c|c|c|c|c|c|c|}
\hline Author & Year & $\mathbf{N}$ & CT & MRI & Myelo-CT & Discography & Treatment & Outcome \\
\hline Lunardi ${ }^{9}$ & 1993 & 1 & $x$ & & & & Discectomy & S \\
\hline \multirow[t]{2}{*}{ Cheng" } & 1994 & 2 & $x$ & $x$ & $x$ & & Hemilaminectomy & S \\
\hline & & & $x$ & $x$ & $x$ & & Hemilaminectomy & S \\
\hline Orrison $^{15}$ & 1982 & I & $x$ & & $x$ & & - & - \\
\hline Kaiser ${ }^{17}$ & 1987 & 1 & $x$ & & $x$ & & - & - \\
\hline Anda ${ }^{8}$ & 1987 & 1 & $x$ & & & & Durotomy & S \\
\hline Anda $^{16}$ & 1988 & 1 & $x$ & & & & Conservative & S \\
\hline $\operatorname{Lee}^{18}$ & 2010 & 1 & $x$ & & $x$ & & $D+C R$ & S \\
\hline Ricca $^{19}$ & 1990 & 1 & $x$ & & $x$ & & $D+C R$ & S \\
\hline Kawaguchi ${ }^{20}$ & 2001 & 1 & $x$ & & $x$ & & $D+C R$ & S \\
\hline Mortensen ${ }^{21}$ & 1991 & 1 & $x$ & & $x$ & & $D+C R$ & S \\
\hline Kaiser ${ }^{22}$ & 1985 & 1 & $x$ & & $x$ & & $D+C R$ & S \\
\hline \multirow[t]{2}{*}{ Bosser $^{23}$} & 1990 & 1 & $x$ & & $x$ & & Puncion por CT & $R$ \\
\hline & & & & & & & $\mathrm{D}$ & S \\
\hline \multirow[t]{4}{*}{ Kakitsubata $^{13}$} & 2009 & 4 & & & & $x$ & Discectomy & S \\
\hline & & & & & & $x$ & Conservative & S \\
\hline & & & & & & $x$ & Open Drainage & S \\
\hline & & & & & & $x$ & Open Drainage & S \\
\hline \multirow[t]{2}{*}{ HIBA } & 2009 & 2 & $x$ & $x$ & & $x$ & $D+C R$ & S \\
\hline & 2017 & & $x$ & $x$ & & & $D+C R$ & $S$ \\
\hline
\end{tabular}

$\mathrm{N}$, numer of patients reported; EMG, electromiogram; X-Rays, radiography; CT, computed tomography; MRI, magnetic resonand imaging; $D$, decompression; CR, cyst resection; S, satisfactory; R, recurrence; HIBA, hospital italiano de buenos aires

\section{Conclusion}

The vacumm phenomenon in the intervertebral spaces is relatively frequent. However, radicular pain caused by gas-containing pseudocyst is an unusual complication and there is no consensus regarding the diagnosis methods.

We consider computed tomography to be the most specific study and we suggest surgical resolution by decompression and microreseccion of the cyst when conservative treatment is not effective. Even though, better level of evidence studies are required to detect recurrence rate and evaluate long-term effectiveness.

\section{Patients consent form}

A retrospectively review of this patients was developed with the approval of our Institutional Review Board (IRB).

\section{Acknowledgements}

None.

\section{Conflict of interest}

None of the presented authors declare to have any conflict of interest and no funding was recived from any institution.

\section{References}

1. Knutsson F. The vacuum phenomenon in the intervertebral discs. Acta Radiologica. 1942;23:173-179.

2. Ford LT, Goodman FG. X-ray studies of the lumbosacral spine. South Med J. 1966;59(10):1123-1128.

3. Raines JR. Intervertebral disc fissures (vacuum intervertebral disc). Am J Roentgenol. 1953;70(6):964-966. 
4. Marr JT. Gas in intervertebral discs. Am JRoentgenol.1953;70(5):804-809.

5. Ford LT, Gilula LA, Murphy WA, et al. Analysis of Gas in Vacuum Lumbar Disc. Am J Roentgenol. 1977;128(6):1056-1057.

6. Ritchie JH. Age changes in lumbar intervertebral discs. Can J Surg. 1970;13(1):65-71.

7. Larde D. Spinal vacuum phenomenon: CT diagnosis and significance. $J$ Comput Assist Tomogr. 1982;6(4):671-676.

8. Anda S. Intradural disc herniation with vacuum phenomenon: CT diagnosis. Neuroradiology. 1987;29(4):407.

9. Lunardi P. Gas-Containing Lumbar Disc Herniation: A Case report and Review of the Literature. Spine. 1993;18(16):2533-2536.

10. Yasuoka H. An unusual case of nerve root compression by intradiscal gas pseudocyst of the lumbar spine. J R Army Med Corps. 2010;156(1):4748.

11. Cheng T. Pneumatic nerve root compression: epidural gas in association with lateral disc herniation. J Neurosurg. 1994;81(3):453-458.

12. Lee CH. Symptomatic gas-containing herniated disc with the vacuum phenomenon: mechanism and treatment. Case report. Neurol Med Chir (Tokyo). 2012;52(2):106-108.

13. Kakitsubata Y. Symptomatic Epidural Gas Cyst Associated With Discal Vacuum Phenomenon. Spine. 2009;34(21):E784-E789.

14. Resnick D. Spinal vacuum phenomena: anatomical study and review. Radiology I 98I; I39(2):34I-348.

15. Orrison WW, Lilleas FG. CT demonstration of gas in a herniated nucleus pulposus. J Comput Assist Tomogr. 1982;6(4):807-808.
16. Anda S, Støvring J, Rø M. CT of extraforaminal disc herniation with associated vacuum phenomenon. Neuroradiology. 1988;30(1):76-77.

17. Kaiser MC, Capesius P, Veiga-Pires JA, et al. Recognition of gascontaining disc herniation on lateral CT-scoutview. Neuroradiology. 1987;29(1):98

18. Lee DY, Lee SH. L2 radicular compression caused by a foraminal extradural gas pseudocyst. J Korean Neurosurg Soc. 2010;47(3):232234.

19. Ricca G, Robertson JT, Hines RS. Nerve root compression by herniated intradiscal gas. Case report. J Neurosurg. 1990;72(2):282-284.

20. Kawaguchi S, Yamashita T, Ida K, et al. Gas-filled intradural cyst of the lumbar spine. Case report. J Neurosurg. 2001;95(2 Suppl):257-259.

21. Mortensen WW, Thorne RP, Donaldson WF. Symptomatic gas-containing disc herniation. Report of four cases. Spine. 1991;16(2):190-192.

22. Kaiser MC, Sandt G, Roilgen A, et al. Intradural disk herniation with CT appearance of gas collection. Am J Neuroradiol. 1985;6(1):117-118.

23. Bosser V, Dietemann JL, Wafter JM, et al. L5 radicular pain related to lumbar extradural gas-containing pseudocyst. Neuroradiology. 1990;31(6):552-553.

24. Kuh SU, Heo DH, Kim KS, et al. Lumbar epidural gas-containing pseudocysts as a cause of severe radicular pain. Joint Bone Spine. 2011;78(4):398-401. 